\title{
Development of Web-Based Platform for Auditory Rehabilitation
}

\author{
Wonjin Lee ${ }^{1,2}$, Junghak Lee ${ }^{2}$ \\ ${ }^{1}$ Audiol Lab, Seoul, Korea \\ ${ }^{2}$ Department of Audiology, Hallym University of Graduate Studies, Seoul, Korea
}

청각재활을 위한 웹 기반 플랫폼의 개발

이 원 진 ${ }^{1,2} \cdot$ 이 정 학

오디올랩1, 한림국제대학원대학교 청각학과 ${ }^{2}$

\begin{abstract}
Purpose: The world has is in the era of the forth industrial revolution where various technologies and services are rapidly improving the quality of life. In the field of auditory rehabilitation, conversion to online services from offline is being attempted based on information and communication technology. The purpose of this study is to develop a web-based platform providing auditory rehabilitation programs. Methods: The business model of the platform was designed based on the concepts and logic of the business model canvas tool. To implement the platform, we analyzed the software requirements and built a server. The usability evaluation was carried out during the prototype stage of the platform development process in order to identify, analyze and address the problems based on the results of the heuristic evaluation. Results: The business model was designed with four major items and nine sub-items. The platform has a web-based physical server and a virtual service environment, and it is now possible to provide auditory rehabilitation programs to specialized institutions such as hearing aid centers, ENT clinics, elderly care facilities, and disabled welfare centers. Usability test results showed that the problem was most severe in error prevention and least severe in minimalism. Conclusion: The web-based platform developed in this study has various advantages such as improvement of service quality, cost reduction, and expansion of market size. The platform can contribute to the online ecosystem of the audiology industry and help strengthen the network of stakeholders. Thus, this platform will enable the development of improved auditory rehabilitation programs.
\end{abstract}

Key Words: Auditory rehabilitation, Platform, Business model, Usability evaluation.

Received: January 9, 2018 / Revised: January 17, 2018 / Accepted: January 18, 2018

Correspondence: Junghak Lee, Department of Audiology, Hallym University of Graduate Studies, 405 Yeoksam-ro, Gangnam-gu, Seoul 06198, Korea Tel: +82-2-2051-4950 / Fax: +82-2-3453-6618 / E-mail: leejh@hallym.ac.kr

\section{INTRODUCTION}

세계는 제4차 산업혁명의 시대로 진입하였으며 정보의 처리 능력, 저장 용량 및 접근성이 기하급수적으로 발전하여 삶의 질을 향상시킬 다양한 기술과 서비스가 빠르게 증가하고 있다 (Schwab, 2017). 헬스케어 분야에서 유전학, 로봇 공학, 나노 기 술, $3 \mathrm{D}$ 프린팅 및 생명공학의 발전은 진단의 정확성과 치료의 효율성을 높였으며, 인공지능과 클라우드 기반의 컴퓨터 시스템 은 지속적인 모니터링과 통합적인 재활 서비스를 가능하게 하였 다(Saniee et al., 2017). 정보통신기술은 이 혁명의 중추라 할 수 있으며 광대역 인터넷은 세계에서 가장 중요한 범용 기술 중 하 나로써 수십억 명의 사람들과 그 주변의 사물들을 웹에 연결하
여 사회와 경제 전반에 영향을 주는 변화를 이끌고 있다.

청각학 분야에서는 다양한 디지털 콘텐츠와 인터넷을 통한 서비스가 개발되고 있으며 전통적인 방식과 비교하여 신뢰성과 효과가 입증되고 있다(Swanepoel \& Hall, 2010). 기존의 연구 를 살펴보면 청각선별검사(Bexelius et al., 2008; Smits et al., 2006), 진단(Choi et al., 2007; Yao et al., 2010), 적합(Ferrari et al., 2009; Ramos et al., 2009), 훈련(Lee, 2017; Sweetow \& Sabes, 2006; Yu et al., 2014), 상담(Laplante-Lévesque et al., 2006) 등 청각재활의 많은 분야에서 온라인 서비스로의 전환 이 이루어지고 있다. 컴퓨터와 인터넷을 이용한 청각재활은 시 간과 비용 측면에서 비용효율적이고, 많은 사람이 적기에 쉽게 진단을 받고 적절한 개입과 중재를 받을 수 있도록 접근성을 높 
이며, 난청인과 청각전문가 간에 상호작용을 크게 증가시키는 등 다양한 이점을 얻을 수 있다(Henshaw et al., 2012). 한 연구 (Thorén et al., 2013)에서는 청각장애인들은 비장애인에 비해 더 많은 노력이 들지만 컴퓨터를 사용하고 인터넷에 접속할 가 능성이 일반적인 인식보다 높으며 청력검사, 상담, 청능훈련 등의 청각재활이 온라인에서 이루어지는 것이 더 유용할 수 있음을 보여주었다.

한국보건산업진흥원(Korea Health Industry Development Institute, 2013)은 2011년도 국내 보청기시장이 최근 5년간 연평 균 $15.3 \%$ 씩 급격하게 성장한 것으로 추정하였으며 동일 제품이 라도 전문센터와 사후관리 서비스에 따라 판매 가격이 다양한 것으로 분석하였다. 고령 인구의 증가와 함께 우리나라에서 보청 기를 구입하는 난청인들이 늘어나고 있지만 병원이나 전문센터 에 따라 보청기 가격이 다르고 보청기 판매와 함께 수반되어야 할 사후관리 서비스를 효과적으로 수행하지 못하는 이유로 청 각재활 콘텐츠와 인식의 부족을 들 수 있다(Baek \& Lee, 2016; Lim \& Bahng, 2016). 청각재활 프로그램의 요구를 조사한 연구 (Hwang et al., 2013)에서는 노인복지관 이용 노인의 대다수가 정기적으로 청력을 평가받기 원하며 보청기, 청취 보조 기기, 청능훈련, 청력보호 및 청력보존 등 다양한 청각관리 프로그램 이 필요한 것으로 나타났다.

본 연구의 목적은 청각재활이 인터넷을 통해 편리하게 이루 어지는 플랫폼을 개발하기 위한 것으로써 청각재활 프로그램 은 성인용 청능훈련 프로그램(Lee et al., 2017)을 사용하였으며 플랫폼 개발은 구체적으로 다음의 세 단계로 이루어졌다.

첫째, 개발할 청각재활 플랫폼의 비즈니스 모델을 설계하여 플랫폼의 개념과 논리를 구조화한다.

둘째, 플랫폼이 청각재활 프로그램을 제공하는 데 필요한 소 프트웨어 요구사항을 분석하여 플랫폼을 구현한다.

셋째, 플랫폼 개발 과정 중 프로토타입 단계에서 사용성 평 가를 통해 플랫폼의 문제점을 분석 및 보완한다.

\section{MATERIALS AND METHODS}

\section{비즈니스 모델}

개발할 청각재활 플랫폼의 개념과 논리를 구조화하고 합리 적이고 체계적으로 묘사하기 위해 비즈니스 모델을 설계하였 다. 비즈니스 모델에 대한 정의는 다양하게 존재하지만 조직이 전략적 목표와 목적을 달성하는 데 필요하여 설계한 협력, 재무, 상호 연관된 구조, 제공할 모든 핵심 제품 및 서비스를 개념, 텍 스트, 그래픽으로 나타낸 관념적 표현으로 정의할 수 있다(AlDebei et al., 2008). 비즈니스 모델은 신생 및 기존 조직의 비즈 니스 논리를 묘사하고 혁신하고 평가하는 도구로 간주하며 정
보통신기술과 관련하여 서술적이고 구조화된 힘을 강조한 많 은 연구자들에게 지지를 받고 있다(Veit et al., 2014). 정보통신 분야의 많은 프로젝트는 순수하게 기술로 시작하여 많은 노력 과 잠재적 이익에도 불구하고 시장에서 성공하기 힘들기 때문에 시장에 대한 적합성을 보장하는 비즈니스 모델을 만드는 일부터 시작하는 것이 바람직한 방법으로 제시된다(Meertens et al., 2012). 본 연구에서는 비즈니스 모델에 대한 다양한 설계 도구 중에서 수익보다는 가치에 중심을 두고 있으며 유용성, 단순성 및 시각적 표현이 장점인 비즈니스 모델 캔버스(Osterwalder \& Pigneur, 2010)를 이용하였다. 비즈니스 모델 캔버스는 9개의 주요 항목으로 구성되어 있으며 각 항목에 대한 개념은 청각재 활 플랫폼의 관점에서 변형하였으며 구체적으로 다음과 같다.

\section{고객분류(Customer segments)}

플랫폼이 제공하는 청각재활 프로그램을 이용하는 사용자 그룹으로서 플랫폼이 제안한 가치에 대해 적절한 대가를 지불 할 의사가 있는 대상을 고객으로 규정한다.

\section{가치제안(Value proposition)}

청각재활 플랫폼이 제안하는 가치로서 현재의 시장이 처한 문제점을 개선하고 필요로 하는 요구를 만족시키며 새로운 방 향을 제시한다.

\section{소통방법(Channels)}

플랫폼이 청각재활 프로그램을 유통 및 판매하고, 고객을 지 원하고, 가치를 평가하며 애프터서비스를 제공하는 등 사용자 그룹과 소통하는 방법이다.

\section{고객관계(Customer relationships)}

고객 확보, 고객 유지, 판매 촉진 등을 고려하여 청각재활 플 랫폼이 사용자 그룹과 어떠한 형태로 관계를 맺을 것인지를 의 미한다.

\section{수익모델(Revenue streams)}

수익을 창출하는 방법으로써 청각재활 프로그램이 제안한 가 치에 대하여 사용자 그룹이 대가를 어떻게 지불하고 싶은지 고 려한다.

\section{핵심자원(Key resources)}

플랫폼이 청각재활 프로그램을 제공하기 위해 필요한 핵심 자원으로써 지적 재산, 인적 자원, 재무 자원 등이 해당된다. 


\section{핵심활동(Key activities)}

플랫폼이 청각재활 프로그램을 제공하기 위해 해야 하는 핵 심활동으로써 비즈니스를 영위하고 운영하는 데 필요한 일들을 의미한다.

\section{핵심관계자(Key partners)}

청각재활 프로그램을 개발 및 공급하기 위해 협업하는 관계 자로서 비즈니스 모델의 최적화, 자원과 인프라의 공유, 위험성 감소 등의 효과를 얻을 수 있다.

\section{비용구조(Cost structure)}

청각재활 프로그램을 제공하기 위해 플랫폼 구축에서부터 운 영까지 발생하는 주요 비용으로써 비용효과를 분석할 수 있다.

\section{플랫폼 구현}

플랫폼은 소프트웨어 요구사항을 분석하여 웹을 기반으로 구현하였다. 소프트웨어 개발에서 요구사항의 분석은 비즈니스 를 이해하고 소프트웨어를 통해 해결해야 할 문제를 최종적으 로 정의하는 것으로써 기획 의도와 개발 결과물의 일치를 위해 중요하다. 정보통신산업진흥원(National IT Industry Promotion Agency, 2012)은 기획 의도에 따라 시스템의 구축 방향이 나 방법이 달라지지만 소프트웨어 개발 이전에 구체적인 시스 템을 정의하기 어렵기 때문에 요구사항을 명확하게 도출하기 위한 11 가지 분류 항목을 제시하였다. 이 분류 항목에 따라 청 각재활 플랫폼의 소프트웨어 요구사항을 분석 및 정의하였으 며 내용은 다음과 같다.

\section{시스템 장비구성}

플랫폼을 구축하기 위해서는 다양한 청각재활 프로그램의 통합된 정보들을 저장하여 운영할 수 있는 서버를 도입할 필요 가 있다. 청각재활 프로그램의 경우 음원 파일의 수와 용량이 상당할 것으로 예상되므로 효율적인 파일 관리와 충분한 저장 공간이 필요하다.

\section{기 능}

소프트웨어는 청각선별검사, 청능훈련, 상담, 보청기 및 센터 검색 등 청각재활 프로그램을 개별적으로 지원하고 관리하는 기능이 필요하며 국가별 언어 선택, 회원 관리, 결제, 메일링, 관 리자 페이지 등 플랫폼 운영을 위한 기능이 필요하다.

\section{성 능}

플랫폼과 청각재활 프로그램의 모든 웹 페이지들은 2초 이 내에 응답하는 것이 적당하다. 인터넷 회선은 음원의 초당 데이
터 전송량과 사용자 수를 고려하여 끊김 없이 재생될 수 있도 록 충분한 데이터 전송속도를 지원해야 한다.

\section{인터페이스}

플랫폼은 웹을 기반으로 개인용 컴퓨터, 태블릿, 스마트폰 등 다양한 기기에서 사용 가능하도록 반응형으로 제작하고, 다양 한 브라우저에서 사용할 수 있도록 표준 기술을 준수한다. 플 랫폼의 그래픽디자인과 프로그램의 동작은 고령 인구의 사용 성과 유니버설 디자인의 원칙을 고려하여 설계한다.

\section{데이터}

시스템 운영에 필요한 사용자 정보와 프로그램 정보는 데이 터베이스를 통해 효율적으로 저장하고 관리한다. 서버에 문제 가 발생하여 데이터를 복구할 수 없는 상황을 대비하여 데이터 는 별도의 저장 장치에 정기적으로 보관한다.

\section{테스트}

플랫폼 개발 과정 중 프로토타입 단계에서 서버에 업로드하 여 잠재적 사용자에게 체험판 형태로 활용하며 웹 기반 소프트 웨어 개발 전문가에게 평가를 의뢰하여 문제점을 분석 및 보완 한다.

\section{보 안}

사용자의 개인 컴퓨터와 서버 사이에 송수신되는 개인정보 는 암호화하여 전송하고 보안서버 인증서를 사용하여 정보 유 출, 위조 및 변조를 방지한다. 서버는 악성 프로그램을 방지하고 치료 및 삭제할 수 있는 서버용 백신 소프트웨어를 설치 및 운 영하고, 자동 업데이트 기능을 사용하여 최신 버전을 유지한다.

\section{품 질}

플랫폼이 제공하는 청각재활 프로그램과 홈페이지 운영에 치명적 결함이 발생한 경우 발견 즉시 사용자에게 문제점과 복 구 예정 시간을 알린다. 또한, 플랫폼은 사용자에게 청각재활 프로그램 이용에 도움을 줄 수 있는 각종 정보들을 주기적으 로 업데이트하고 업데이트한 내용은 홈페이지 게시와 메일로 알린다.

\section{제약사항}

청각재활 프로그램의 이용을 위해 사용자의 컴퓨터 기기에 별도의 소프트웨어 설치는 최대한 지양하고 브라우저를 통한 접속과 쉬운 조작만으로 프로그램 사용이 가능하도록 설계한 다. 하나의 계정으로 다수의 기기에 동시에 접속하는 것은 제한 하고 동시에 접속할 경우 안내 메시지와 함께 이전 기기에서의 
접속을 자동으로 해제한다.

프로젝트 관리

플랫폼에서 제공하는 청각재활 프로그램은 불법복제를 비롯 한 각종 저작권 침해로부터 보호받을 수 있는 방안을 마련한다. 데이터 분석에 활용할 수 있는 모든 정보와 통계는 시스템에서 추출하여 관리자 페이지에서 볼 수 있는 기능을 구현한다.

\section{프로젝트 지원}

서버에 문제가 발생하거나 운영상에 문제가 발생한 경우 이 를 해결 및 개선할 수 있는 관리자를 두고 관리자가 플랫폼과 청각재활 프로그램 운영의 문제점을 지속적으로 감시할 수 있 는 시스템을 구축한다.

\section{사용성 평가}

플랫폼 개발 과정 중 프로토타입 단계에서 사용성 평가를 통해 문제점을 발견하고 이를 해결하고자 하였다. 본 연구에서 는 소프트웨어의 사용성을 평가하기 위한 방법으로써 발견적 평가(heuristic evaluation)를 선택하였다. 발견적 평가의 목적 은 사용자 환경 설계와 관련된 문제점을 식별하기 위한 것으로 써 직관적이고 사용하기 쉬우며 합리적인 비용으로 개발 초기 과정에서 사용할 수 있다는 장점이 있다. 평가자는 평가하는 소 프트웨어에 관련한 전문가이어야 하며 1 2시간 내에 평가를 완료 할 수 있다. 사용성 문제는 두 명의 평가자가 $50 \%$ 이상, 다섯 명은 약 70\% 이상, 15명은 90\%를 확인할 수 있다(Nielsen, 1995). 본 평 가에서는 Nielsen(1994)이 제안한 좋은 사용자 환경 설계를 위 한 10 가지 주요 원칙을 바탕으로 청각재활 플랫폼의 특성에 초 점을 맞추어 발견적 평가의 원칙을 재구성하였으며 내용은 다 음과 같다.

\section{일관성(Consistency)}

청각재활 플랫폼은 사용자들이 혼란스럽지 않도록 같은 방 법과 태도를 유지하며 웹 관련 표준에 부합하도록 설계한다.

\section{친숙성(Metaphor)}

청각재활 플랫폼은 사용자에게 친숙한 개념을 사용하며 사 용자들이 기대하는 자연스럽고 논리적인 순서로 프로그램을 구성한다.

\section{가시성(Visibility)}

청각재활 플랫폼은 사용자에게 합리적인 시간 내에 피드백을 통해서 현재 수행 중인 상황에 대한 정보를 제공할 수 있도록 웹 페이지를 구성한다.
효율성(Efficiency)

청각재활 플랫폼은 사용자들이 프로그램을 빠르고 편리하 게 사용할 수 있도록 설계하며 효율적으로 구성한다.

\section{기억성(Memory)}

청각재활 플랫폼은 사용자가 프로그램을 직관적으로 사용 할 수 있어야 하며 사용법은 기억하기 쉽도록 설계한다.

\section{자율성(Freedom)}

청각재활 플랫폼은 사용자가 프로그램을 사용하면서 실수 를 하더라도 자유롭게 제어할 수 있는 방법을 제공한다.

\section{간결성(Minimalism)}

청각재활 플랫폼의 시스템은 필수적인 내용만 간단명료하게 제시하며 최소한의 입력만을 요구한다.

\section{심미성(Aesthetic)}

청각재활 플랫폼은 장애인, 노인 등 사회적 약자를 배려하고 화면을 알아보기 쉽게 디자인하며 접속 기기에 따라 조화로운 화면을 제공한다.

\section{오류방지(Error prevention)}

청각재활 플랫폼은 시스템이 사용자의 실수를 미연에 방지할 수 있도록 설계하며 오류가 발생할 경우 사용자가 이를 인식할 수 있어야 한다.

\section{도움정도(Helpfulness)}

청각재활 플랫폼의 시스템 메시지는 사용자의 입장에서 이 해하기 쉽게 제공해야 하며 프로그램 사용에 도움을 줄 수 있 는 자료가 적절히 제공되어야 한다.

청각재활 플랫폼 설계 시 고려되어야 하는 발견적 평가의 원 칙이 구성된 후 인간-컴퓨터 상호작용(human-computer interaction) 및 사용자 경험(user experience) 전문가의 자문을 받 아 체크리스트를 작성하였다. 체크리스트는 다양한 소프트웨 어 개발에 활용된 기존의 발견적 평가를 참고하였으며 2시간 이내에 평가가 이루어질 수 있도록 핵심적 사항만으로 구성하 였다. 최종적으로 체크리스트는 사용성 원칙에 따라 3 개의 문 항씩 총 30개 문항으로 구성되었다(Appendix). 평가에는 웹 기 반 소프트웨어 개발 관련 전문가 15 명이 참여하였다. 평가자들 은 평가에 앞서 프로그램의 개요와 사용자의 배경정보를 제공 받았으며 프로토타입 형태인 청각재활 플랫폼의 모든 기능을 충분히 사용한 후 평가를 진행하였다. 평가보고서에는 체크리 스트의 각 문항에 대한 객관적 평가와 함께 사용성 문제가 발 
생한 위치나 상황을 주관적으로 기입하였다. 객관적 평가는 각 체크리스트 문항에 대한 문제의 심각도 등급을 0 4단계로 구 분하여 이루어졌으며 각 단계의 의미는 다음과 같다.

0 : 사용성에 문제가 전혀 없습니다.

1: 간과할 수 있는 문제입니다. 이 문제는 별다른 조치를 취 하지 않을 수도 있습니다.

2: 사소한 문제가 발견됩니다. 낮은 우선순위로 이 문제를 해 결해야 합니다.

3: 주요한 문제가 발견됩니다. 높은 우선순위로 이 문제를 해 결해야 합니다.

4: 심각한 문제가 발견됩니다. 서비스를 개시하기 전 이 문제 를 필히 해결해야 합니다.

\section{RESULTS}

\section{비즈니스 모델}

설계한 비즈니스 모델을 Figure 1에 제시하였다. 청각재활 플 랫폼의 비즈니스 모델은 공급자(provider), 고객(customer), 생 산기반(infrastructure) 재무(finance)의 4가지 큰 항목으로 분 류할 수 있으며 세부적으로는 가치제안(value proposition), 고 객분류(customer segments), 고객관계(customer relationships), 소통방법(channels), 핵심관계자(key partners), 핵심활동(key activities), 핵심자원(key resources), 비용구조(cost structure), 수익모델(revenue streams)의 9 가지 항목으로 이루어져 있다.

청각재활 플랫폼의 비즈니스 모델에서 공급자는 플랫폼을 통해 서비스 품질의 향상, 시장 규모의 확대, 매출 증가, 비용
감소, 사업 확장의 용이, 진입 장벽의 감소 등 다양한 가치를 제 안한다. 제안한 가치에 대가를 지불하는 고객은 보청기센터, 이 비인후과, 노인복지시설, 청능재활실 및 장애인복지관 등의 전 문기관으로 분류되었다. 청각재활 프로그램은 플랫폼의 웹사 이트에 접속하여 이용할 수 있으며 소셜 미디어와 학술지 등을 통해 사용자 그룹과 소통한다. 플랫폼은 청각재활 서비스를 제 공하는 전문기관에서 필요로 하는 요구를 스스로 해결하도록 수단과 방법을 제공하고 자동화된 프로세스를 통해 프로그램 과 콘텐츠의 사용권한을 거래한다.

비즈니스 모델의 생산기반에서 정부, 대학 및 연구소 등이 핵 심관계자로 설계되었다. 플랫폼의 핵심활동은 청각재활 서비스 에 대한 기획과 프로그램 및 콘텐츠 연구개발이며 정부, 대학 및 연구소와 협력 관계를 구축하여 수행할 수 있다. 청각재활 의 개별 프로그램과 콘텐츠는 지적재산권으로 보호받는 회사 의 중요한 자원이 되며 정부의 개발 지원금은 중요한 금전적 재 원이다. 플랫폼이 청각재활을 제공하기 위해 발생하는 핵심 비 용은 소프트웨어 개발 비용과 서버관리 비용이다. 플랫폼의 수 익은 기본적으로 각각의 프로그램과 콘텐츠를 지속적으로 이 용할 권한을 판매함으로써 창출되며 월간, 연간 및 평생 이용 료 방식이 될 수 있다.

\section{플랫폼 구현}

소프트웨어 요구사항을 분석하여 설계한 청각재활 플랫폼의 시스템 구조는 Figure 2 와 같다. 플랫폼의 시스템 구조는 다양 한 이해관계자(stakeholder)들이 인터넷을 통해 자유롭게 네트 워크형성(networking)이 되도록 웹을 기반으로 설계하였다. 플

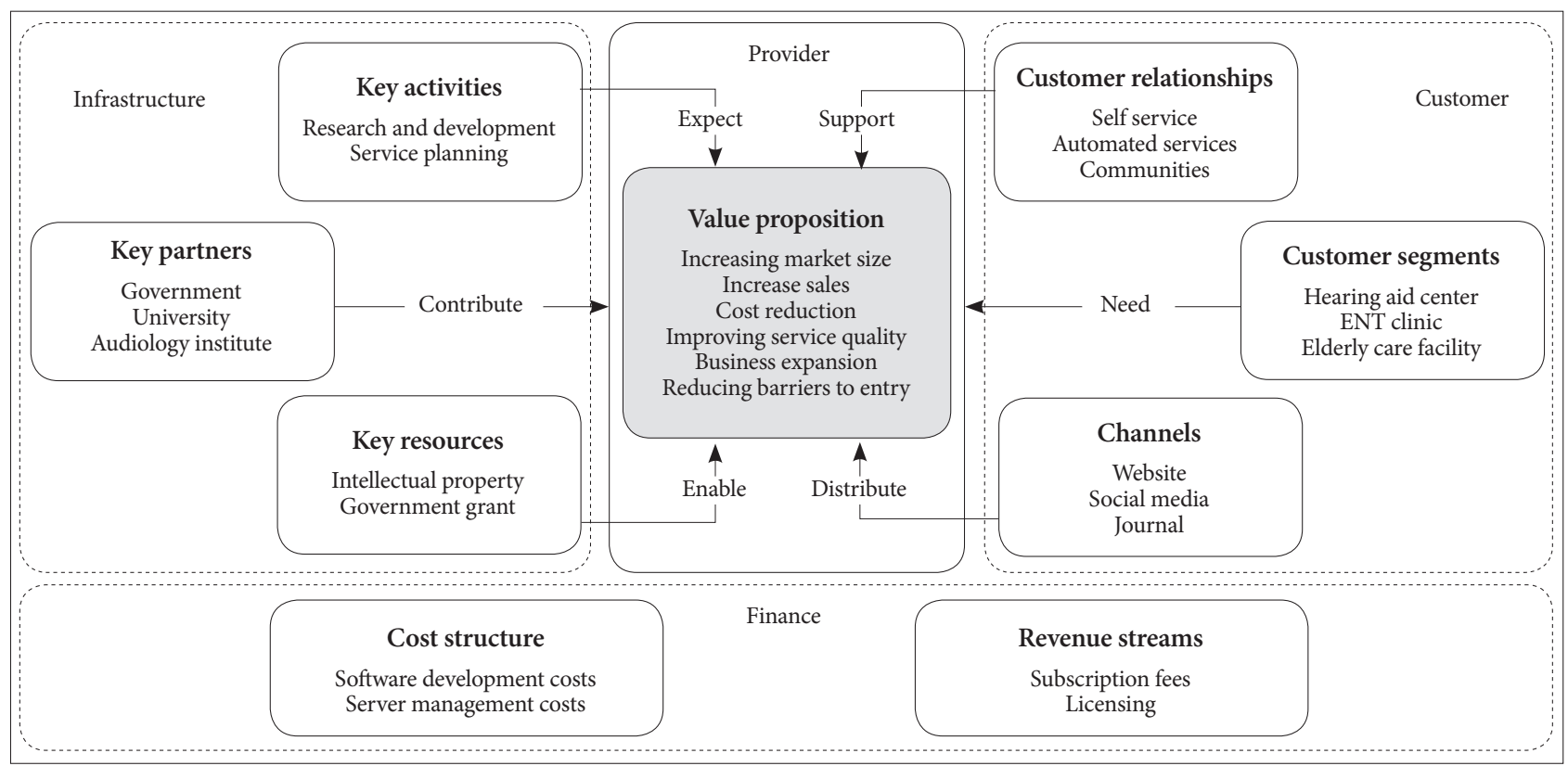

Figure 1. Business model of the web-based platform for auditory rehabilitation. 
랫폼은 청각선별검사, 청능훈련, 컨설팅 등 다양한 서비스(service)를 탑재할 수 있으며 국가별 언어 선택, 회원 관리, 결제, 메일링, 관리자 페이지 등의 기본적인 기능을 지원하도록 구현 하였다. 서버(server)는 다양한 청각재활 프로그램의 통합된 정 보들을 저장하고 운영하기 위하여 데이터베이스를 구축하였고, 플랫폼이 청각재활 프로그램을 제공하며 사용자와 상호응답하 기 위한 웹 어플리케이션을 구성하였다. 사용자 환경(user interface)은 다양한 브라우저 간에 동일하게 보여지도록 웹 표준 을 준수하여 설계하였고 화면을 구성하는 요소들은 다양한 컴 퓨터 기기의 접속 환경을 고려하여 디자인하였다.

청각재활 프로그램은 인터넷을 통해 자유롭게 접속하여 이 용할 수 있으나 여러 명의 사용자가 하나의 계정을 공유하는 것을 방지하기 위해 IP 주소를 확인하여 서버에 동시 접근을 제한하도록 설계하였다. 서버의 장비는 서비스 초기인 점을 감 안하고 사용자 수와 시스템의 크기를 고려하여 $10 \mathrm{Mbps}$ 의 기본 회선을 지원하는 HP DL320G8 V2 (Hewlett-Packard, Palo Alto, CA, USA)모델을 선정하였으며 저장 공간은 1 Terabyte 를 할당하였다. 서버의 운영체제는 리눅스를 사용하였으며 데 이터베이스 서버와 웹 어플리케이션 서버 두 부분으로 나누어 구성하였다. 데이터베이스는 기본적으로 사운드, 이미지 및 회 원정보 등의 데이터를 관리하고 웹 어플리케이션은 사용자의 요청에 대한 응답과 프로그램의 동작을 실행한다. 데이터베이 스 관리 시스템은 청각재활 플랫폼의 특성을 고려하여 데이터 를 효율적으로 저장하고 관리하기 위해 문서형을 지향하는 MongoDB를 사용하였다. 청각재활 프로그램은 채점, 난이도 선택, 음원 재생, 소음 제거 등의 기능을 구현하고 사용자와 상 호응답하는 웹 어플리케이션을 구성하기 위해 Node JS의 Ex- press를 사용하였다. 저장공간의 많은 부분을 차지하는 프로그 램의 음원 파일은 모두 MPEG-1 Audio Layer 3 형식으로 변환 하였으며 원본 파일은 별도의 저장장치에 따로 보관하였다. 청 각재활 플랫폼의 사용자 환경은 사용자가 청각재활 프로그램을 사용하며 발생하는 각각의 상황을 시스템이 처리하는 구조를 설계하기 위해 자바스크립트, HTML, CSS, AngularJS를 사용 하였다.

플랫폼은 개인 컴퓨터, 태블릿, 스마트폰 등 다양한 기기에 따라 최적화된 사용자 환경을 제공할 수 있도록 부트스트랩을 이용하여 그리드 반응형으로 디자인하였다. 화면의 배치, 색상 의 명도 대비, 글씨 크기, 대체 텍스트는 고령 인구가 쉽게 프로 그램을 사용할 수 있도록 주의를 기울였다. 사용자의 컴퓨터와 서버 사이에 이루어지는 통신 과정에서 개인정보가 유출되거 나 훼손되는 것을 방지하기 위해 SSL 보안서버 인증서를 사용 하였다. 서버에는 백신 소프트웨어를 설치하였으며 악성 프로 그램 경보가 발령되거나 보안 업데이트 공지가 있는 경우에 업 데이트를 자동으로 실시하도록 설정하여 감염을 예방할 수 있 도록 대비하였다.

\section{사용성 평가}

청각재활 플랫폼 개발 과정 중 프로토타입 단계에서 실시한 사용성 평가의 결과는 Figure 3에 나타내었다. 사용성 평가에 는 웹 기반 소프트웨어 개발에 관련된 전문가 15 명이 참여하였 다(프로그래머: 7명, 디자이너: 4명, 연구원: 4명). 사용성 평가 에 소요된 시간은 평가자에 따라 15 분에서 4 시간으로 평균 한 시간 정도 걸렸으며 직업군에 따라 연구원, 디자이너, 프로그래 머 순으로 오래 걸렸다. 평가자들은 모두 10 개의 사용성 원칙

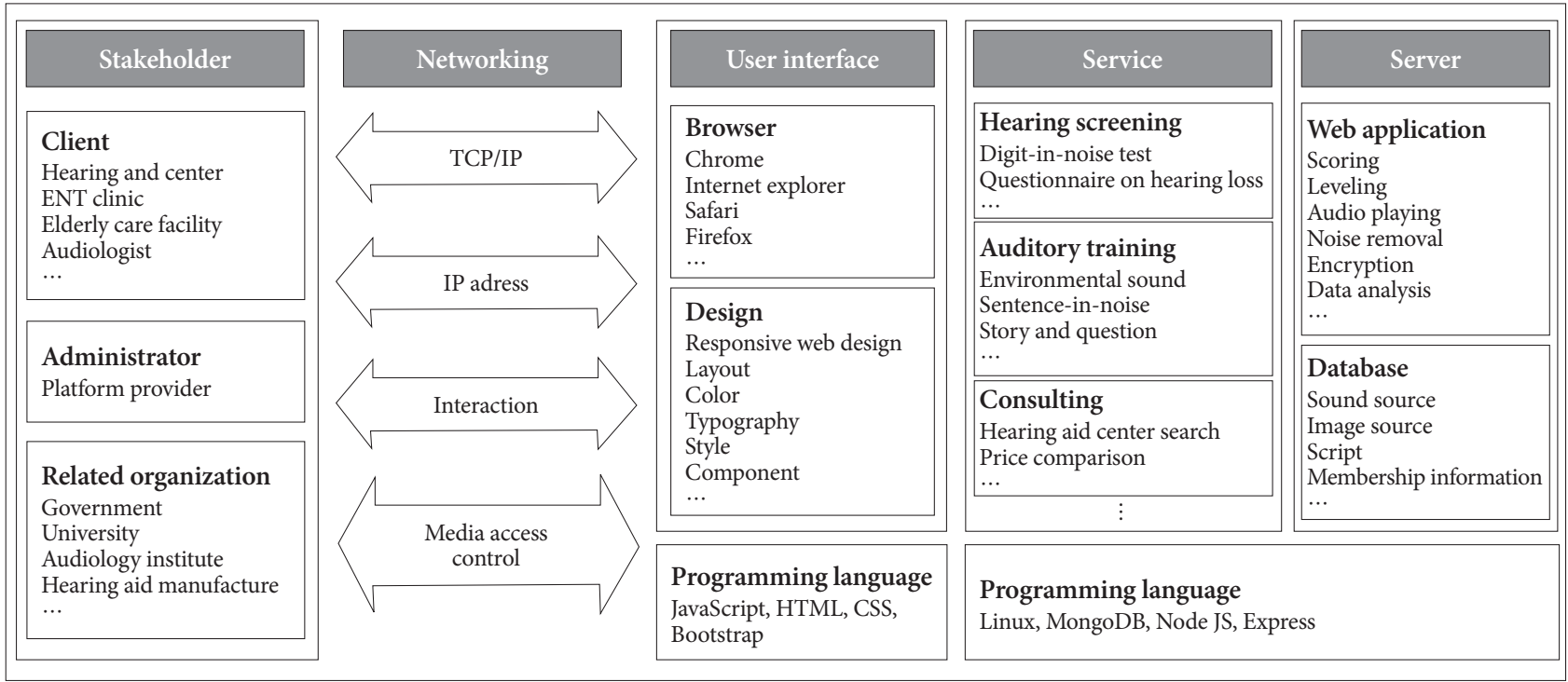

Figure 2. System structure of the web-based platform for auditory rehabilitation. TCP: transmission control protocol, IP: internet protocol. 
Figure 3. Overall results of the usability evaluation (10 category, 5-point rating scale, 15 subjects). Severity rating scale; 0 : No problem, 1: Cosmetic problem only, 2: Minor problem, 3: Major problem, 4: Usability catastrophe.

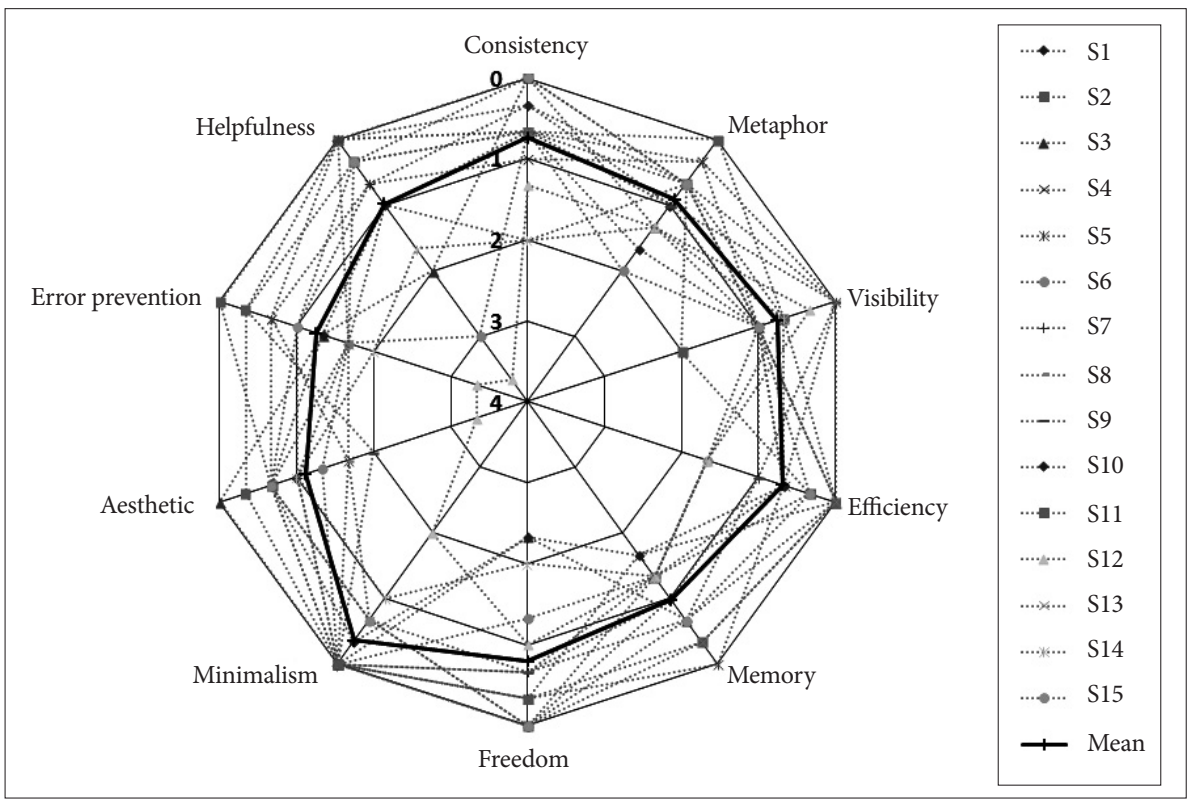

에 따라 3 개의 문항씩 총 30 개 문항의 체크리스트에 문제의 심 각성을 0 4의 숫자로 평가하였다.

사용성 평가 결과 원칙별 평균은 문제의 심각성이 높은 항 목부터 오류방지 1.24[standard deviation (SD) = 0.83], 심미성 $1.11(\mathrm{SD}=0.81)$, 도움정도 $0.98(\mathrm{SD}=1.14)$, 기억성 $0.98(\mathrm{SD}=$ $0.51)$, 친숙성 $0.91(\mathrm{SD}=0.54)$, 자율성 $0.80(\mathrm{SD}=0.83)$, 가시성 $0.76(\mathrm{SD}=0.53)$, 일관성 $0.73(\mathrm{SD}=0.63)$, 효율성 $0.69(\mathrm{SD}=$ $0.61)$, 간결성 0.36(SD = 0.57)으로 나타났다.

평가보고서에는 체크리스트에 대한 객관적 평가 이외에도 문제가 발생한 위치나 상황을 주관적으로 평가하였다. 15 명의 평가자가 주관적으로 발견한 주요 문제점은 청각재활 프로그 램 수행 과정에서 사용자가 실수하는 오류방지의 문제, 특정 화면비율에서 프로그램의 사용성을 해치는 심미성의 문제, 청 각재활 프로그램의 목적 및 효과와 사용방법에 대한 설명이 부 족한 도움정도의 문제, 프로그램의 지시사항이 직관적이지 못 하고 버튼의 모양이 사용자가 기대하는 의미와 다른 기억성의 문제, 프로그램 진행 과정이 사용자가 기대하는 순서와 다른 친숙성의 문제, 사용자가 프로그램을 제어할 수 없는 자율성의 문제, 프로그램 수행 과정에서 수행 위치를 확인할 수 없는 가 시성의 문제, 영어와 한글이 혼재되어 있는 일관성의 문제, 사 용자에게 편리한 환경을 제공하지 못하는 효율성의 문제였으 며, 간결성에서는 별다른 문제가 발견되지 않았다.

\section{DISCUSSIONS}

\section{비즈니스 모델}

우리나라에서 보청기 보급률은 양측 $40 \mathrm{~dB} \mathrm{HL}$ 이상의 대상
자를 기준으로 $12.6 \%$ 에 불과하며 다른 나라에서 보고한 자료 와 비교하면 상대적으로 낮은 수준으로 보청기 사용의 장벽을 줄이기 위한 노력이 필요한 것으로 보인다(Cho et al., 2010). 청 각재활 플랫폼이 제안하는 가치들은 오프라인에서 이루어지는 청각재활이 온라인으로 전환이 이루어지면서 얻을 수 있는 이 점이 가장 크게 작용할 수 있다. 청각재활의 집적화와 디지털화 를 통해 잠재된 보청기 사용자의 접근성을 높인다면 청각산업 의 시장 규모는 확대될 수 있을 것이다. 한 연구(Martin, 2007) 에서는 컴퓨터 프로그램을 이용한 청각재활은 시간과 비용 측 면에서 비용효율이 높으며 보청기 반품률을 현저하게 감소시키 는 등 보청기 공급자의 이익을 증가시키는 것으로 보고하였다. 보청기 판매와 함께 수반되어야 할 청각재활을 효과적으로 제 공하지 못하는 원인이 도구의 부족에 있다면 플랫폼은 이를 해 결해 줄 수 있다. 플랫폼은 전문기관에서 개별적으로 청각재활 에 필요한 도구를 개발하는 비용과 수고를 덜어 청각전문가가 난청인의 의사소통능력 향상에 전념할 수 있도록 도울 수 있다. 다양하고 전문화된 청각재활은 보청기 구매에 대한 난청인의 불안 요인을 상당 부분 불식시켜 줄 수 있으며 보청기 사용 만 족감을 높일 수 있을 것이다.

플랫폼의 비즈니스 모델은 기업과 기업 사이의 거래를 기반으 로 한다. 플랫폼은 청각재활 프로그램과 콘텐츠에 대한 소유권 을 판매하지는 않으며 라이센싱을 통해 다른 기업에게 지적재 산권의 사용을 허가한 후 사용료를 받아 이익을 창출할 수 있 다. 청각재활이 필요한 개인은 자신이 받을 수 있는 서비스의 유 형과 해당 기관에 대한 정보를 플랫폼을 통해 안내 받을 수 있 으며 직접적인 서비스는 개인이 선택한 기관의 청각전문가를 통 해 최종적으로 이루어진다. 인터넷을 통한 청각재활은 청력 상 
실의 위험성, 청력의 중요성, 전문가 개입의 필요성에 대한 대중 의 인식을 향상시킬 수 있으나 서비스 과정과 방법에 대한 현재 의 이해는 불완전하며 상당한 경험적 조사와 검증이 필요하다 (Swanepoel, 2010). 플랫폼은 전문가의 역할을 대체하지 않으며 전문기관에서 개인에게 더 효율적이고 전문적인 서비스를 편리 하게 제공할 수 있도록 도구를 제공하며 긴밀한 네트워크를 구 성하도록 돕는다.

청각산업에서 무형인 청각재활 서비스에 대한 비용은 보통 보청기나 인공와우 등 유형의 제품에 포함되는 경우가 많다. 우 리나라의 보청기센터에서는 보통 보청기적합을 위한 간단한 청 각검사를 무료로 제공하는 편이며 정부에서는 재활치료 서비 스 이용권을 지원하고 보청기 구매에 대한 지원금을 지급하는 등 보청기에 대한 개인의 부담을 줄이기 위해 노력하고 있다. 청각재활 플랫폼은 보청기 등의 청각 기기와 함께 청각재활을 개인에게 제공하여 이익을 창출하는 전문기관이 비용을 지불 하는 것이 타당한 것으로 보인다. 청각재활 플랫폼의 핵심활동 은 청각재활 프로그램을 정부의 정책 방향과 계획에 따라 기획 하며, 대학 및 연구소와 인력, 보유기술, 연구시설 및 장비 등을 공동으로 활용하여 연구개발하는 것으로 볼 수 있다. 청각재활 플랫폼의 모든 활동에서 재무 관련 사항이 발생하지만 많은 비 용이 청각재활 프로그램과 콘텐츠 연구개발에 집중되며 인건 비가 많은 부분을 차지한다. 소프트웨어의 시스템은 해당 청각 재활 서비스가 요구하는 기능의 다양성, 복잡성, 정확성, 질적 수준에 따라 크기와 구현방법이 결정된다. 서버는 인터넷을 통 해 청각재활 프로그램과 콘텐츠를 이용할 수 있게 해주는 기본 장비로써 필수적으로 구축해야 하지만 사용자 수, 전송되는 데 이터의 양, 데이터 처리 속도에 따라 비용이 급격하게 증가하므 로 추후 서버 증설계획 등을 세워 신중히 고려할 필요가 있다. 정부는 고령화사회로 진입함에 따라 60 대 이후에 급격하게 증 가하는 청각장애인의 건강을 관리하는 것이 의료비 지출 감소 및 사회복지 재정 악화 예방에 크게 기여를 하므로 난청을 조 기진단하고 재활하는 방법을 마련하는 데에 적극적으로 지원 할 필요가 있다(Gang et al., 2013).

\section{플랫폼 구현}

본 연구에서는 웹 기반의 물리적 서버와 가상의 서비스 환경 을 구축하여 청각재활 플랫폼을 개발하였다. 플랫폼을 운영하 기 위한 기본적인 시스템을 구현함으로써 보청기센터, 이비인 후과, 노인복지시설, 청능재활실, 장애인복지관 등의 기관에 청 각재활 프로그램과 콘텐츠를 제공하는 것이 가능해졌다. 보청 기센터를 비롯한 전문기관은 플랫폼에 접속하여 청각재활이 필요한 난청인에게 더욱 효과적으로 서비스를 제공할 수 있으 며 정부와 연구자가 기획 및 개발한 청각재활 프로그램은 플랫
폼을 통해 보급 및 확산이 용이해졌다.

플랫폼은 네트워크 효과의 힘에 의존하며 사용자가 더 많은 관심을 가지게 될수록 가치는 증폭되므로 플랫폼을 중심으로 생태계를 조성하고 이해관계자들을 적극적으로 유치할 필요가 있다. 본 연구에서 개발한 청각재활 플랫폼은 정부, 대학, 연구 소 및 보청기 관련 전문기관의 협력과 상호작용을 바탕으로 하 고 있으며 모든 이해관계자가 새로운 프로그램과 콘텐츠 개발 에 적극적인 참여를 필요로 한다. 현재의 플랫폼은 전문기관에 서 청각재활이 필요한 개인들에게 쉽게 도움을 줄 수 있도록 기본적인 기능과 도구들을 제공하지만 청각재활의 종류와 콘 텐츠가 다양하지는 못하다. 우리나라는 노화를 비롯한 감각기 능의 저하에서 오는 심리적 불안, 정서적 불안, 사회적 소외감 등을 해소시켜 줄 수 있는 서비스와 콘텐츠가 매우 부족한 실정 이며 사회문제로서 그 심각성을 더하고 있다(Gang et al., 2013). 향후 플랫폼을 활용한 다양한 청각재활과 콘텐츠 개발에 대한 연구가 활발히 이루어진다면 난청인의 의사소통능력 향상과 국민 보건복지 향상에 더욱 기여할 수 있을 것으로 기대된다.

\section{사용성 평가}

청각재활 플랫폼의 사용성 평가 결과 크고 작은 문제들을 발 견하였으며 심각성이 높은 문제를 위주로 보완하였다. 문제의 심각성은 10 개의 사용성 원칙 중 오류방지에서 가장 높게 나타 났으며 주요 원인과 해결방법은 다음과 같다. 첫째, 청각재활 프 로그램 수행 과정에서 사용자가 기대하는 입력 위치를 시스템 이 따라가지 못하여 사용자의 실수가 발생하였다. 이 문제는 프 로그램의 두 번째 단위의 입력 값이 시작될 때 시스템이 입력 위치를 자동으로 이동하여 해결하였다. 두 번째 문제점은 사용 자가 한글 입력이 필요한 상황에서 영문으로 잘못 입력하는 경 우가 있으므로 시스템이 한글과 영문을 제어하여 해결하였다. 세 번째 문제점은 스마트폰에서 접속하였을 경우 버튼을 선택 할 때 버튼의 크기와 간격이 충분하지 못하여 사용자가 실수하 는 경우가 발생하였다. 이는 청각재활 플랫폼의 화면을 16:9 비 율의 17 인치 모니터를 기준으로 디자인한 후 다른 환경에 따라 다양하게 반응하도록 적용하는 과정에서 발생한 문제였으며 화면의 남는 공간을 활용하여 충분한 크기의 버튼으로 교체할 예정이다.

심미성은 두 번째로 심각성이 높은 항목으로 특정 화면비율 의 스마트폰에서 글씨가 겹쳐서 나타나고 버튼들이 자연스럽게 배치되지 못하여 프로그램을 사용할 수 없는 문제가 발생하였 다. 또한 고령자가 스마트폰으로 접속할 경우 글씨 크기가 작아 가독성이 떨어질 수 있으며, 강조한 내용의 글씨 크기가 일반적 인 내용의 글씨 크기와 비교하여 뚜렷한 차이를 보이지 못하였 다. 심미성의 문제점을 해결하기 위해 화면의 구성요소들을 스 
마트폰 환경에 맞도록 전반적으로 수정할 계획이다.

오류방지와 심미성을 제외한 나머지 8개 원칙에서는 비교적 낮은 점수를 획득하였다. 도움정도에서는 제공하는 청각재활 프로그램의 목적 및 효과에 대한 설명이 필요하며 프로그램 사 용방법에 대한 정보가 부족한 것으로 나타났다. 이는 청각재활 프로그램의 진행 과정과 방법을 익힐 수 있는 연습 프로그램을 제공하고 프로그램의 목적과 효과에 대한 문서를 제공하여 문 제를 해결할 수 있다. 기억성의 주요 문제는 프로그램 수행을 위해 제시한 지시사항이 직관적이지 못하며 버튼의 모양이 사 용자가 기대하는 의미와 다를 수 있다는 점이다. 지시사항은 문구를 추가하여 보충 설명하고 버튼은 새로 디자인하여 교체 할 예정이다. 친숙성에서는 청각재활 프로그램이 정해진 수행 횟수가 끝나면 메인 화면으로 돌아가는 부분에서 사용자가 기 대하는 바와 다를 수 있는 것으로 나타났다. 이 문제는 사용자 가 청각재활 프로그램을 반복해서 수행하는 기능을 추가하고 프로그램 수행을 마쳤을 때 결과에 대한 피드백을 추가하여 해 결할 예정이다. 자율성의 문제는 프로그램이 음원을 재생할 때 정지, 일시정지, 속도조절 등 사용자가 음원 재생을 제어할 수 없는 것으로 나타났으며 재생 옵션을 추가하여 해결할 예정이 다. 가시성의 문제는 사용자가 선택한 프로그램이 무엇인지, 프 로그램 수행 과정에서 어느 정도의 단계에 있는지 명확히 인지 할 수 없다는 점이었다. 이 문제는 프로그램 화면의 상단에 자 신이 선택한 메뉴를 항상 보여주고 수행 단계를 나타내어 해결 하였다. 일관성의 문제는 영어와 한글이 혼재되어 있어 한글로 통일시킬 필요가 있는 것으로 나타났으며 영어 사용을 최대한 자제하고 한글화를 통해 해결할 것이다. 효율성은 사용자에게 편리한 환경을 제공하기 위해 개선되어야 하는 것으로 평가되 었으며 키보드 단축키를 활용하고 사용자가 환경을 설정하는 기능을 추가하여 보완할 예정이다. 간결성은 청각재활 프로그 램의 심플한 디자인과 간편한 사용성으로 별다른 문제가 발견 되지 않았으며 가장 낮은 점수를 획득하였다.

발견적 평가 결과를 토대로 청각재활 플랫폼의 문제점을 분 석하고 보완하였지만 모든 문제점을 해결하지는 못하였다. 상 기의 미해결 문제점들을 보완하면 플랫폼의 사용자에게 더욱 편리하고 효율적인 청각재활 프로그램과 콘텐츠를 제공할 수 있을 것이다. 향후 청각선별검사, 상담, 생애주기별 청능훈련 등 다양한 청각재활 프로그램과 콘텐츠의 연구개발이 필요하며 본 연구에서 개발한 플랫폼이 보급 및 확산에 기여하게 되기를 기대한다.

중심 단어 : 청각재활·플랫폼·비즈니스 모델·사용성 평가.

Acknowledgments

본 연구는 한국콘텐츠진흥원의 2017년도 창업발전소 콘텐츠 스타
트업 육성지원사업의 지원을 받아 수행한 연구임.

\section{REFERENCES}

Al-Debei, M. M., El-Haddadeh, R., \& Avison, D. (2008). 14th Americas Conference on Information Systems: Defining the Business Model in the New World of Digital Business. Toronto, ON: Sheraton Centre Toronto.

Baek, S. S. \& Lee, J. H. (2016). Development of crossword puzzles for auditory training. Audiology and Speech Research, 12(2), 103-108.

Bexelius, C., Honeth, L., Ekman, A., Eriksson, M., Sandin, S., Bagger-Sjöbäck, D., et al. (2008). Evaluation of an internet-based hearing test-comparison with established methods for detection of hearing loss. Journal of Medical Internet Research, 10(4), e32.

Cho, Y. S., Choi, S. H., Park, K. H., Park, H. J., Kim, J. W., Moon, I. J., et al. (2010). Prevalence of otolaryngologic diseases in South Korea: Data from the Korea national health and nutrition examination survey 2008. Clinical and Experimental Otorhinolaryngology, 3(4), 183-193.

Choi, J. M., Lee, H. B., Park, C. S., Oh, S. H., \& Park, K. S. (2007). PC-based tele-audiometry. Telemedicine Journal and E-Health, 13(5), 501-508.

Ferrari, D. V. \& Bernardez-Braga, G. R. (2009). Remote probe microphone measurement to verify hearing aid performance. Journal of Telemedicine and Telecare, 15(3), 122-124.

Gang, S., Ban, S., \& Cha, J. (2013). A Study on the Construction of Convergence Smart Ecosystem for New Silver Generation. (pp. 187-188). Gwacheon: Ministry of Science, ICT and Future Planning.

Hwang, J. H., Shin, E. Y., \& Kim, J. S. (2013). A study on hearing self-status and aural rehabilitation program needs of the elderly who attend geriatric welfare. Audiology and Speech Research, 9(2), 175-189.

Henshaw, H., Clark, D. P., Kang, S., \& Ferguson, M. A. (2012). Computer skills and internet use in adults aged 50-74 years: influence of hearing difficulties. Journal of Medical Internet Research, 14(4), el13.

Korea Health Industry Development Institute. (2013). Medical Device Market Research Report 12. (pp. 1-52). Cheongju: Korea Health Industry Development Institute.

Laplante-Lévesque, A., Pichora-Fuller, M. K., \& Gagné, J. P. (2006). Providing an internet-based audiological counselling programme to new hearing aid users: A qualitative study. International Journal of Audiology, 45(12), 697-706.

Lee, W., Lee, J., Lee, K., Lee, J., \& Bahng., J. (2017). The twentieth Korean Academy of Audiology Conference: Introduction of Web-Based Korean Auditory Training Program. Gyeongsan: Catholic University of Daegu.

Lee, Y. (2017). Mobile application development for improving auditory memory skills of children with hearing impairment. Audiology and Speech Research, 13(1), 50-61.

Lim, E. H. \& Bahng, J. (2016). Preliminary study for development of auditory training tool using story and question. Audiology and Speech Research, 12(2), 109-114.

Martin, M. (2007). Software-based auditory training program found to reduce hearing aid return rate. The Hearing Journal, 60(8), 32-35.

Meertens, L. O., Iacob, M. E., Nieuwenhuis, L. J., van Sinderen, M. J., Jonkers, H., \& Quartel, D. (2012). The 27th annual ACM symposium on applied computing: Mapping the Business Model Canvas to ArchiMate. Trento, Trentino-Alto Adige: University of Trento.

National IT Industry Promotion Agency. (2012). Software Business Requirements Analysis and Application Guide. (pp. 13-70). Seoul: National IT industry promotion agency.

Nielsen, J. (1994). Usability Engineering. (pp. 115-148). San Diego, CA: Academic Press.

Nielsen, J. (1995, January 1). How to Conduct a Heuristic Evaluation. Nielsen Norman Group. Retrieved from https://www.nngroup.com/articles/ how-to-conduct-a-heuristic-evaluation/.

Osterwalder, A. \& Pigneur, Y. (2010). Business Model Generation: A Handbook for Visionaries, Game Changers, and Challengers. New York, NY: John Wiley \& Sons.

Ramos, A., Rodriguez, C., Martinez-Beneyto, P., Perez, D., Gault, A., Fal- 
con, J. C., et al. (2009). Use of telemedicine in the remote programming of cochlear implants. Acta Oto-Laryngologica, 129(5), 533-540.

Saniee, I., Kamat, S., Prakash, S., \& Weldon, M. (2017). Will productivity growth return in the new digital era? An analysis of the potential impact on productivity of the fourth industrial revolution. Bell Labs Technical Journal, 20, 2-20.

Schwab, K. (2017). The Fourth Industrial Revolution. New York, NY: Crown Business.

Smits, C., Merkus, P., \& Houtgast, T. (2006). How we do it: The Dutch functional hearing-screening tests by telephone and internet. Clinical Otolaryngology, 31(5), 436-440.

Swanepoel de, W. \& Hall, J. W. 3rd. (2010). A systematic review of telehealth applications in audiology. Telemedicine and e-Health, 16(2), 181-200.

Sweetow, R. W. \& Sabes, J. H. (2006). The need for and development of an adaptive Listening and Communication Enhancement (LACE) pro- gram. Journal of the American Academy of Audiology, 17(8), 538-558.

Thorén, E. S., Oberg, M., Wänström, G., Andersson, G., \& Lunner, T. (2013). Internet access and use in adults with hearing loss. Journal of Medical Internet Research, 15(5), e91.

Veit, D., Clemons, E., Benlian, A., Buxmann, P., Hess, T., Kundisch, D., et al. (2014). Business models. Business and Information Systems Engineering, 6(1), 45-53.

Yao, J., Wan, Y., \& Givens, G. D. (2010). Using web services to realize remote hearing assessment. Journal of Clinical Monitoring and Computing, 24(1), 41-50.

Yu, J., Chun, H., Song, C. G., \& Han, W. (2014). Case study of speech perception enhancement in hearing-impaired adult by auditory training program of mobile device. Audiology and Speech Research, 10(2), 158168. 


\title{
APPENDIX
}

\section{Heuristic Evaluation Checklist for the Web-Based Platform for Auditory Rehabilitation}

\author{
발전적 평가(Heuristic Evaluation)
}

안녕하세요? 본 평가의 결과는 개발 중인 '온라인 청각서비스 플랫폼'의 서비스 향상과 학술연구를 위해 사용됩니다. 현재 홈페 이지에 프로토타입의 플랫폼을 공개하였습니다. 'www.audiollab.co.kr'에 접속하시어 회원가입, 국가별 언어 선택, 제품, 연구 등 의 모든 메뉴와 청각재활 프로그램을 충분히 사용하신 후 평가를 시작하여 주시기 바랍니다. 평가는 0 4의 숫자로 ( ) 안에 표기 바라며, 사용성에 문제가 발견된 경우, 해당 상황이나 위치를 재확인하시고 질문 아래에 함께 기입하여 주시기 바랍니다. 평 가에 사용하는 각 숫자의 의미는 아래와 같습니다. 숫자는 높을수록 사용성에 문제가 없습니다.

$0:$ 사용성에 문제가 전혀 없습니다.

1: 간과할 수 있는 문제입니다. 이 문제는 별다른 조취를 취하지 않을 수도 있습니다.

2: 사소한 문제가 발견됩니다. 낮은 우선순위로 이 문제를 해결해아 합니다.

3: 주요한 문제가 발견됩니다. 높은 우선순위로 이 문제를 해결해야 합니다.

4: 심각한 문제가 발견됩니다. 서비스를 개시하기 전 이 문제를 필히 해결해야 합니다.

1. 일관성(Consistenchy)

a. 시스템 전반에 걸쳐 일관된 구조와 이름을 사용하고 있습니까? ( )

b. 시스템의 상호작용을 위해 사용된 요소들의 기능과 동작은 웹 관련 표준과 일반적인 규칙을 준수하고 있습니까? ( )

c. 화면의 디자인 요소들이 일관성 있는 스타일과 폼을 사용하고 있습니까? ( )

문제가 발견된 경우 기입란

\section{2. 친숙성(Metaphor)}

a. 일반적인 인터넷 사용자 수준에 맞추어 친숙한 개념으로 단어, 문구, 용어가 사용되었습니까? $(\quad)$

b. 레이아웃, 색상, 버튼의 심벌 등 시각적 요소들이 사용자들에게 친숙한 개념으로 디자인되었습니까? ( )

c. 각각의 프로세스는 사용자들이 기대하는 자연스럽고 논리적인 순서로 이벤트가 진행됩니까? ( )

문제가 발견된 경우 기입란

\section{3. 가시성(Visibility)}

a. 현재 수행 중인 단계나 상태를 파악할 수 있는 정보를 제공합니까? ( )

b. 화면상에서 선택할 대상과 대상의 상태(ex. 선택 여부)에 대한 정보를 적절히 제공합니까? ( )

c. 현재의 접속환경(ex. 인터넷 속도)을 고려하여 합리적인 시간 내에 피드백을 제공합니까? ( )

\section{문제가 발견된 경우 기입란}

\section{4. 효율성(Efficiency)}

a. 시스템의 상호작용을 위해 사용된 요소들은 수행 중인 직업이 편리하도록 설계되었습니까? ( )

b. 신속한 수행을 위해 메뉴 계층의 구조가 적절히 설계되었습니까? ( )

c. 홈페이지에서 사이트의 모든 메뉴로 신속한 이동이 가능합니까? ( ) 


\section{5. 기억성(Memory)}

a. 현재 단계의 수행을 위해 이전 단계를 기억할 필요가 적도록 설계되었습니까? ( )

b. 레이아웃, 색상, 버튼의 심벌 등 시각적 요소들이 사용자들이 기억하기 쉽도록 디자인되었습니까? ( )

c. 작업 수행을 위해 필요한 지침과 정보는 현재 화면에 적절히 제공됩니까? ( )

문제가 발견된 경우 기입란

\section{6. 자율성(Freedom)}

a. 사용자가 선택하거나 입력한 내용을 자유롭게 취소, 수정 및 재실행할 수 있습니까? ( )

b. 사용자는 언제든지 프로그램을 종료할 수 있으며 다시 시작하기 용이합니까? ( )

C. 사용자가 수행 중인 단계를 건너뛰거나 이전 단계로 자유롭게 이동할 수 있습니까? ( )

문제가 발견된 경우 기입란

\section{7. 간결성(Minimalism)}

a. 직업 수행을 위해 필요한 지침과 정보는 불필요하거나 지나치게 많이 제공되지 않으며 간단명료하게 제시됩니까? ( )

b. 레이아웃, 색상, 버튼의 심벌 등 시각적 요소들은 간결하게 디자인되었습니까? ( )

c. 사용자는 최소한의 입력만으로 원하는 기능을 수행할 수 있습니까? ( )

문제가 발견된 경우 기입란

\section{8. 심미성(Aesthetic)}

a. 이미지, 색채, 배경 등의 화면 구성요소들은 사회적 약자(ex. 고령자)를 배려하여 디자인되었습니까? ( )

b. 서체, 글씨 크기, 행간 및 자간 등은 가독성을 높일 수 있도록 디자인되었습니까? ( )

c. 접속 기기(ex. 모바일)와 화면의 비율에 따라 화면의 구성요소들은 적절히 배치되고 있습니까? ( )

문제가 발견된 경우 기입란

\section{9. 오류방지(Error prevention)}

a. 사용자의 실수를 미연에 방지할 수 있도록 입력 값을 적절히 제한합니까? ( )

b. 사용자가 메뉴의 항목이나 버튼 등을 선택할 때(특히, 모바일 환경에서) 실수하지 않도록 충분한 크기와 간격을 제공합니까? ( )

C. 사용자가 실수하여 문제가 발생했을 경우 이를 인식할 수 있도록 프로그램이 설계되었습니까? ( )

\section{문제가 발견된 경우 기입란}

\section{0. 도움정도(Helpfulness)}

a. 시스템 메시지는 코드(ex. Error 404)가 아닌 사용자의 언어로 도움을 주고 있습니까? ( ）

b. 시스템 메시지는 사용자의 문제를 정확히 파악하고 적절한 솔루션을 제공합니까? ( )

c. 프로그램 사용에 도움을 줄 수 있는 자료가 적절히 제공되고 있습니까? ( )

문제가 발견된 경우 기입란 